\title{
Development of Laser-Produced Tin Plasma-Based EUV Light Source Technology for HVM EUV Lithography
}

\author{
Junichi Fujimoto, ${ }^{1}$ Tsukasa Hori, ${ }^{2}$ Tatsuya Yanagida, ${ }^{2}$ and Hakaru Mizoguchi1 \\ ${ }^{1}$ EUV Development Division, Gigaphoton Inc., 400 Oaza Yokokurashinden Oyama-shi, Tochigi-ken 323-8558, Japan \\ ${ }^{2}$ EUV Development Division, Gigaphoton Inc., 3-25-1 Shinomiya Hiratsuka-shi, Kanagawa-ken 254-8555, Japan
}

Correspondence should be addressed to Junichi Fujimoto, junichi_fujimoto@gigaphoton.com

Received 10 May 2012; Accepted 20 June 2012

Academic Editor: Sergi Gallego

Copyright (C) 2012 Junichi Fujimoto et al. This is an open access article distributed under the Creative Commons Attribution License, which permits unrestricted use, distribution, and reproduction in any medium, provided the original work is properly cited.

\begin{abstract}
Since 2002, we have been developing a carbon dioxide $\left(\mathrm{CO}_{2}\right)$ laser-produced tin ( $\mathrm{Sn}$ ) plasma (LPP) extreme ultraviolet (EUV) light source, which is the most promising solution because of the $13.5 \mathrm{~nm}$ wavelength high power $(>200 \mathrm{~W})$ light source for high volume manufacturing. EUV lithography is used for its high efficiency, power scalability, and spatial freedom around plasma. We believe that the LPP scheme is the most feasible candidate for the EUV light source for industrial use. We have several engineering data from our test tools, which include $93 \% \mathrm{Sn}$ ionization rate, $98 \% \mathrm{Sn}$ debris mitigation by a magnetic field, and $68 \% \mathrm{CO}_{2}$ laser energy absorption rate. The way of dispersion of Sn by prepulse laser is key to improve conversion efficiency (CE). We focus on prepulsed laser pulsed duration. When we have optimized pulse duration from nanosecond to picosecond, we have obtained maximum $4.7 \%$ $\mathrm{CE}\left(\mathrm{CO}_{2}\right.$ laser to EUV; our previous data was 3.8\%) at $2 \mathrm{~mJ}$ EUV pulse energy. Based on these data we are developing our first light source as our product: "GL200E." The latest data and the overview of EUV light source for the industrial EUV lithography are reviewed in this paper.
\end{abstract}

\section{Introduction}

Since 2002, Gigaphoton/Komatsu have been developing a laser plasma produced (LPP) extreme ultraviolet (EUV) light source based upon carbon dioxide $\left(\mathrm{CO}_{2}\right)$ laser-produced tin (Sn) plasma. The $\mathrm{CO}_{2}$-Sn-LPP EUV light source is deemed to be the most promising solution, as the $13.5 \mathrm{~nm}$ wavelength high power $(>200 \mathrm{~W})$ light source for high volume manufacturing (HVM) EUV lithography (EUVL) [1-4], because of the high efficiency, power scalability, and spatial freedom around plasma. Therefore, we have chosen the LPP-EUV method. We believe that the $\mathrm{CO}_{2}$-Sn-LPP scheme is the most feasible candidate for the EUV light source for HVM.

In order to meet the performance requirements for an EUV light source, we have focused on three enabling technologies:

(1) high conversion efficiency (CE), efficiency from $\mathrm{CO}_{2}$ laser to EUV light energy;
(2) debris mitigation functionality, Sn debris mitigation from optical components;

(3) $\mathrm{CO}_{2}$ laser power usage, efficiency $\mathrm{CO}_{2}$ laser energy into $\mathrm{Sn}$.

We have investigated how Sn droplets under laser irradiation generate EUV light. Also investigated is Sn behavior, in vacuum environment, under irradiation of laser beams.

In this paper, we report on the present development status of our LPP light source for EUVL for HVM.

\section{LPP EUV Light Source Equipment Configurations}

The typical setup of an EUV light source system is shown in Figure 1.

Our EUV light source contains, four primary sections:

(1) EUV vessel including droplet generator and collector mirror; 


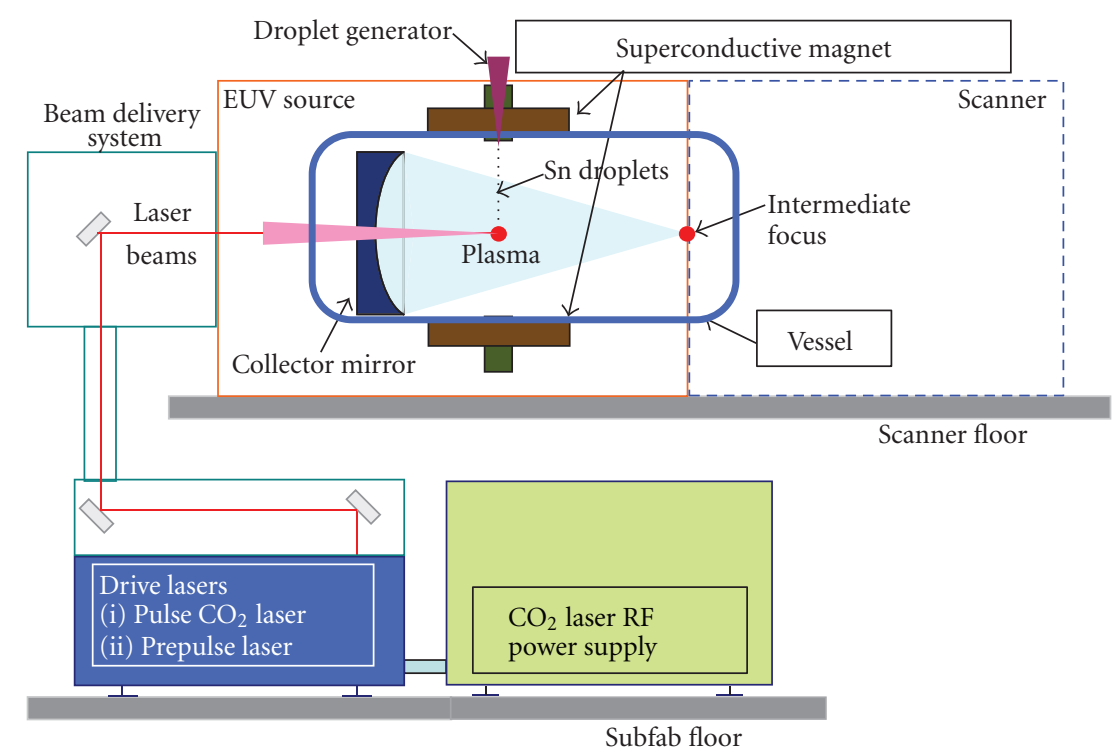

FIGURE 1: Typical layout of an LPP EUV light source.

(2) superconductive magnets for tin debris mitigation;

(3) plasma generation drive lasers, composed of prepulse laser and pulsed $\mathrm{CO}_{2}$ laser;

(4) $\mathrm{CO}_{2}$ laser RF power supply system.

We are developing LPP-EUV light source based upon an experimental system. The small experimental light source tool is employed for Sn target shooting optimization. The features of this system are shown below. The GL200E proto system is used for system performance demonstration. Our target is to develop the GL200E system, which will be our first generation HVM EUV light source based upon the GL200E proto system.

2.1. Small Experimental Light Source Tool (Figure 2). We have investigated EUV plasma generation scheme with the use of the small experimental tool operated at the repetition rate of $10 \mathrm{~Hz}$ (maximum). Figure 2 shows the experimental setup for the basic investigation of EUV light generation and Sn debris mitigation [5-7].

The small experimental light source setup simulates the final system, except for the repetition rate of the driver laser and can be operated with and without magnetic field applied. It can simulate a $20 \mathrm{~kW} \mathrm{CO}$ laser with pulse energy of $200 \mathrm{~mJ} /$ pulse at low repetition rate of less than $10 \mathrm{~Hz}$. The setup has various diagnostic features where $\mathrm{Sn}$ can be observed throughout the entire process from droplet generation to EUV plasma generation.

This tool is capable of simulating conditions of EUV light generation identical to those in GL200E, such as pulse duration, pulse energy of $\mathrm{CO}_{2}$ laser, prepulse laser, Sn droplet size, and magnetic field environment with the only significant difference that it operates at a maximum repetition rate of $10 \mathrm{~Hz}$. The tool's compactness makes it easier to measure results and optimize various plasma generation parameters.
The small experimental tool consists of various sub systems, including, a short-pulsed high-energy $\mathrm{CO}_{2}$ laser, a prepulse laser, a Sn droplet generator, and a EUV vacuum vessel with a solenoid magnet. By using this tool, we are able to investigate EUV light emission under sequential prepulse laser and a $\mathrm{CO}_{2}$ laser irradiation conditions. The development purpose for small experimental system is primarily debris mitigation analysis, $\mathrm{Sn}$ droplet and plasma formation and $\mathrm{CO}_{2}$ laser energy consumption budget experiments.

2.2. GL200E Proto System (Figure 3). The prototype system of our first high volume manufacturing (HVM) EUV light source has a $100 \mathrm{kHz} 20 \mathrm{~kW} \mathrm{CO}$ laser, $20 \mu \mathrm{m}$ in diameter droplet generator, and magnetic field debris mitigation functionality.

The development purpose for the GL200E proto system is integration of all functionalities, testing and debugging based upon a HVM configured EUV light source. This system is planned to be integrated to a scanner system and to demonstrate actual lithographic performance. The target system specifications are shown in Table 1. The HVM system is required to balance many key performance aspects, such as: reliability, maintainability, footprint compactness and affordable operational cost.

\section{Enabling Functions to Meet EUV Light Source Performance}

There are some high level performance requirements necessary to be realized in order for LPP-EUV light source to be successful in the industry, high clean EUV power and EUV source reliability/availability for high volume continuous fab operation. In this section, we would like to discuss and demonstrate the basic enabling functionalities we are developing, in order to achieve the necessary performance. 


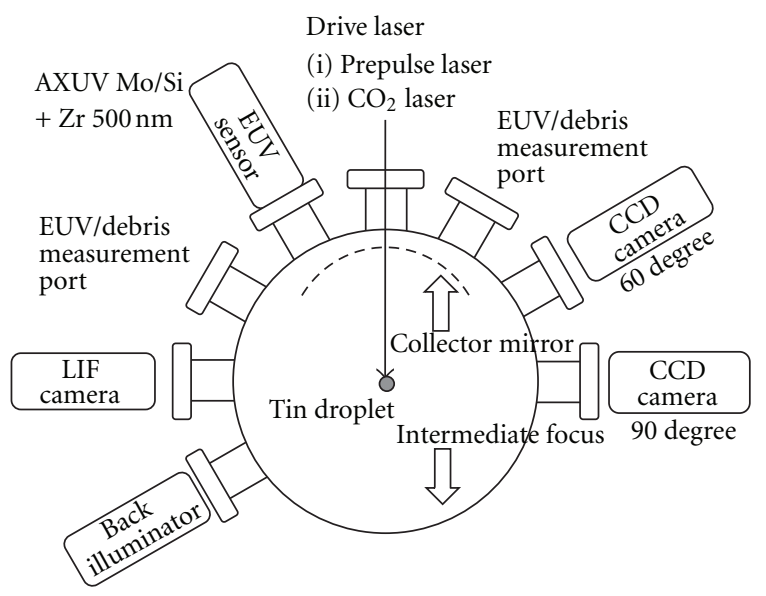

FIGURE 2: Diagram of small experimental tool.

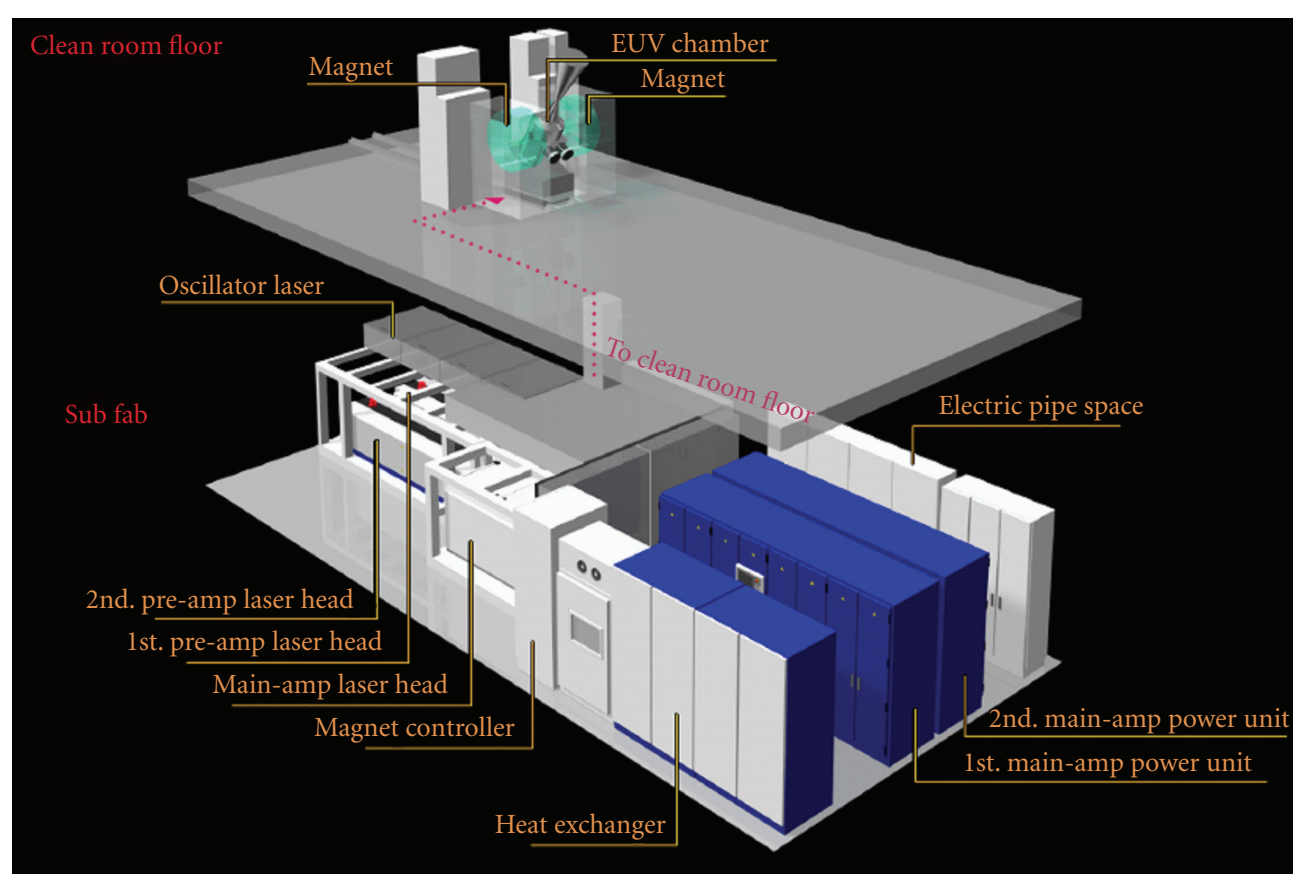

FIGURE 3: LPP EUV source system layout; Gigaphoton GL200E.

TABLE 1: Target specification of EUV source, GL200E for HVM.

\begin{tabular}{|c|c|c|}
\hline Model number & Units & Gigaphoton GL200E \\
\hline EUV clean power (at I/F) & $\mathrm{W}$ & 250 (in-band; after filtering IR and DUV) \\
\hline EUV pulse energy (at I/F) & $\mathrm{mJ}$ & $\sim 2.5$ \\
\hline Max. rep. rate & $\mathrm{kHz}$ & $\sim 100$ \\
\hline Max. $\mathrm{CO}_{2}$ laser system & $\mathrm{kW}$ & $20(100 \mathrm{kHz}, 200 \mathrm{~mJ} /$ pulse $)$ \\
\hline Target material and shape & & Liquid Sn droplet, spherical \\
\hline Droplet size (diameter) & $\mu \mathrm{m}$ & $10-30$ \\
\hline Plasma creation scheme & & Double-pulse laser shooting \\
\hline Debris mitigation scheme & & Hybrid: magnetic field guiding and chemical etching \\
\hline
\end{tabular}




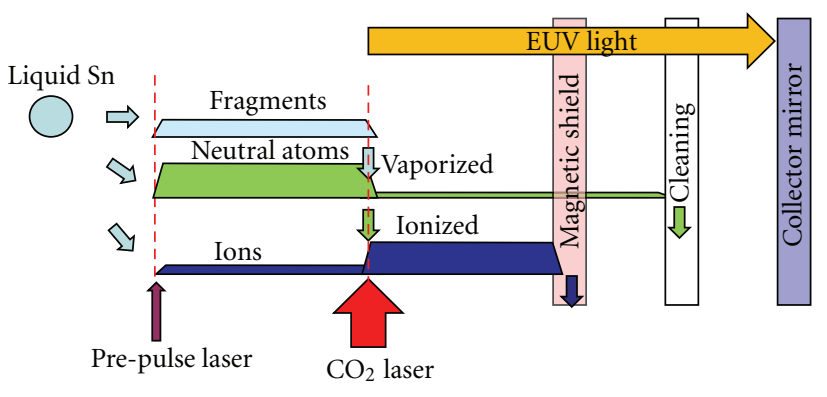

FIgURE 4: Droplet to Sn debris mitigation concept.

The basic enabling functionalities are:

(1) Double pulse laser irradiation;

(2) Sn debris mitigation by magnetic field.

Each function will be discussed at length in the following sections.

3.1. Double-Pulse Laser Irradiation. When a Sn droplet target is irradiated with a prepulse laser (wavelength $1.06 \mu \mathrm{m}$ ) beam and/or a $\mathrm{CO}_{2}$ laser (wavelength $10.6 \mu \mathrm{m}$ ) beam, the Sn droplet in the vessel is converted into a plasma emitting EUV where several states of Sn exist simultaneously $[6,7]$. Sn present during plasma generation is generally classified in three categories: fragments, neutral atoms, or ions. After emitting EUV light residues of the plasma are eventually scattered inside the vessel. To prevent the collector mirror from being contaminated, Sn debris needs to be trapped before being deposited onto the collector mirror surface or cleaned after deposition. This Sn-state scheme is shown in Figure 4.

To enhance EUV energy and to minimize Sn debris towards the collector mirror, the ionization of the Sn should be maximized in the laser irradiation processes. We believe that the shape of the Sn target is crucial [8-12]. To realize this, a double-laser irradiation process is utilized in our system. The theoretical [13] and experimental [14] data have clearly demonstrated the advantage of combining a laser beam at a wavelength of a $\mathrm{CO}_{2}$ laser with $\mathrm{Sn}$ plasma to achieve high CE from driver laser pulse energy to EUV inband energy [15].

The Sn fragments are generated during the prepulse irradiation. The Sn fragments are, at that moment, the majority of the Sn present. Fragments can reach a maximum of a few micrometers in diameter. The $\mathrm{Sn}$ fragments were measured by a shadowgraph method. Figure 5 shows the shadowgraphs of the fragments after the prepulse laser irradiation for the droplet with $20 \mu \mathrm{m}$ diameter. The droplet is irradiated by a prepulse laser originating from left hand side in the image. During laser irradiation, the Sn droplet is displaced away from the irradiation point while simultaneously expanding in diameter. Figure 5(e) shows the images after the prepulse laser irradiation without the main $\mathrm{CO}_{2}$ laser irradiation. Figure 5(c) shows the images with the main $\mathrm{CO}_{2}$ laser irradiation. Figure 5(d) is captured immediately after the EUV light emission. When irradiation condition is optimized, the fragments have disappeared from the shadowgraph image.

The CE with the droplet target is measured. A CE of $3.5 \%$, using $20 \mu \mathrm{m}$ diameter droplet and $200 \mathrm{~mJ} \mathrm{CO}_{2}$ laser irradiation, has been demonstrated by optimizing the prepulse laser conditions as shown in Figure 6. We also have obtained greater than $3.7 \% \mathrm{CE}$, using $28 \mu \mathrm{m}$ droplet and $200 \mathrm{~mJ} \mathrm{CO}_{2}$ laser energy irradiation. These data indicate that prepulse is very effective to enable high CE no dependence on droplet size in this range.

We have thus demonstrated the possibility to reduce the debris by use of a smaller $20 \mu \mathrm{m}$ diameter droplet target without degradation in CE. These basic studies, together with theoretical calculations, have contributed to the basic design and development of a high-power production machine capable for further EUV power scaling.

Figure 7 shows the clean EUV pulse energy (defined as "clean EUV" after filtering out of non-EUV band energy) obtained as a function of droplet size and $\mathrm{CO}_{2}$ laser pulse energy using an optimal prepulse laser condition. Using the small experimental light source tool, and calculating based upon a targeted pulse repetition rate of $100 \mathrm{kHz}$, we have demonstrated using a $20 \mu \mathrm{m}$ droplet that $1.55 \mathrm{~mJ} /$ pulse clean EUV pulse energy is achieved and therefore $>150 \mathrm{~W}$ clean EUV power is possible. Further we demonstrated using a $40 \mu \mathrm{m}$ droplet that $2.52 \mathrm{~mJ}$ clean EUV pulse energy is experimentally observed. Again, calculating for a $100 \mathrm{kHz}$ system, we can demonstrate that $>250 \mathrm{~W}$ clean EUV power is achievable. It should be noted that with the use of the larger $40 \mu \mathrm{m}$ droplet, debris increased dramatically compared to the $20 \mu \mathrm{m}$ Sn droplet case. Therefore, in the future work, we will work further to optimize the $20 \mu \mathrm{m}$ Sn droplet experiment to target $>250 \mathrm{~W}$ clean EUV power.

3.2. Sn Debris Mitigation by Magnetic Field. Our Sn debris mitigation is a simple concept based upon making use of a magnetic field capturing and channeling charged Sn ions away from critical parts of the EUV source system. During the process of EUV plasma creation, obtaining the optimum ratio of the three Sn categories (fragments, neutral atoms, and ions) is important from a debris mitigation perspective. When our double-pulse irradiation scheme and small droplets are combined, the majority of Sn ions are able to be trapped as $\mathrm{Sn}^{\mathrm{n}+}$ within the magnetic field. The ionization rate of $\mathrm{Sn}$ will be described below in this section.

In order to mitigate Sn debris, a pair of superconductive magnetic coils is arranged on opposite sides of the vessel. In reality, however, not all of the Sn atoms and ions can be trapped in the magnetic field. Accordingly, our system is also equipped with a chemical etching mechanism. This chemical etching mechanism is designed to mitigate any remaining Sn atoms that could not have been trapped in the magnetic field and can potentially be deposited on the collector mirror surface or other optically sensitive locations.

The amount and the distribution of the Sn neutral atoms after the prepulse laser irradiation in a certain magnetic field were observed with a laser induced fluorescence (LIF) 


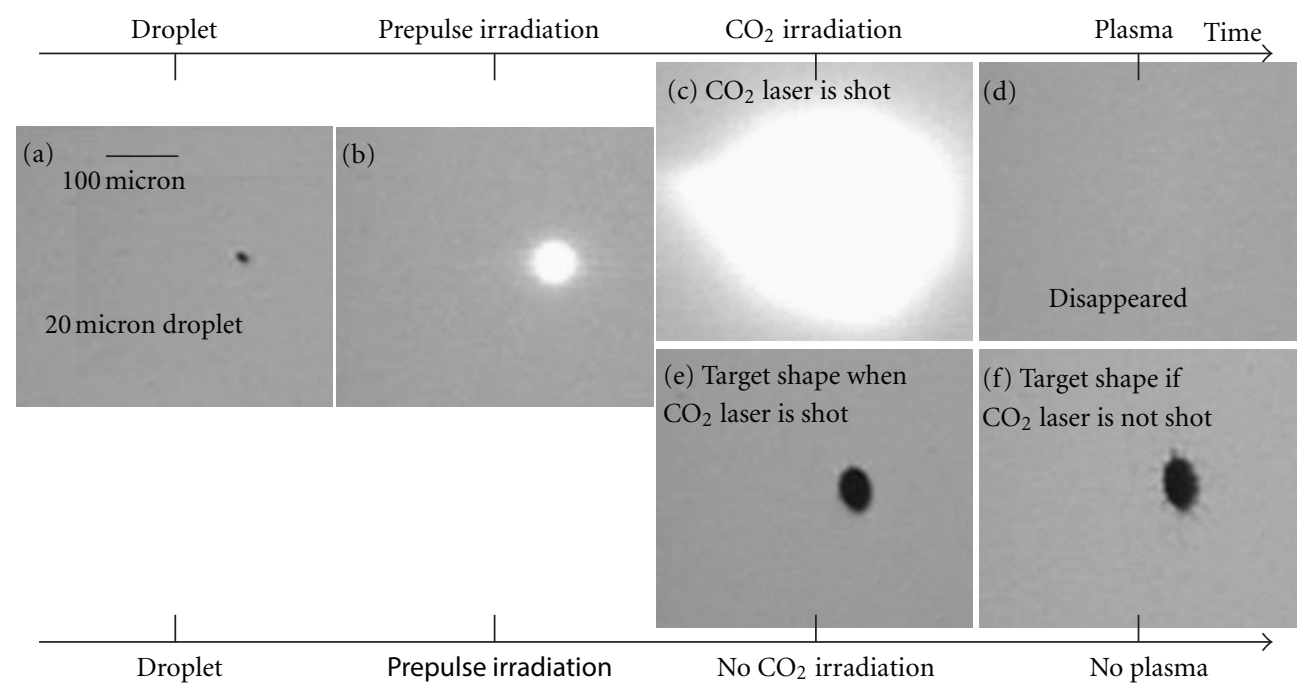

FIgURE 5: Shadowgraph images of Sn fragments.

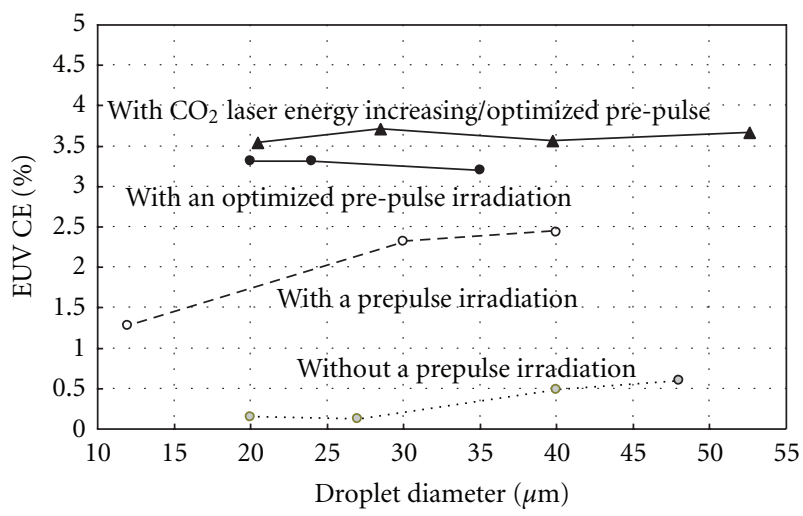

- $\mathrm{CO}_{2}$ laser: $100 \mathrm{~mJ}$

A $\mathrm{CO}_{2}$ laser: $200 \mathrm{~mJ}$

Figure 6: CE as a function of the droplet diameter.
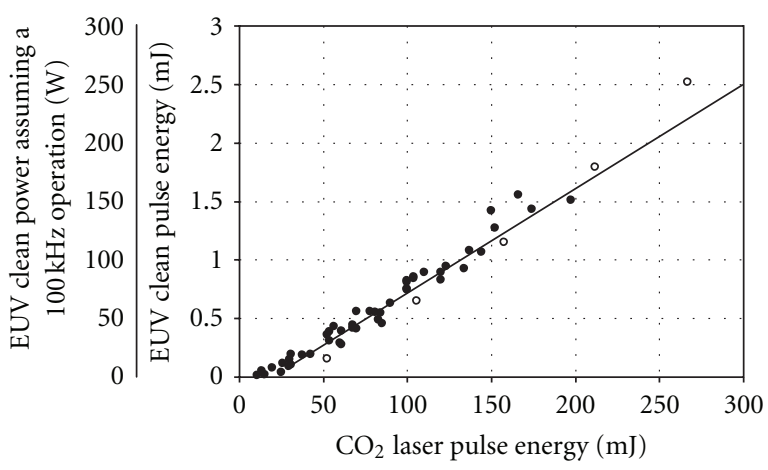

- Dloplet diameter 20-micron meter

- Droplet diameter 40-micron meter

With optimized prepulse irradiation

FIgURE 7: $\mathrm{CE}$ as a function of the $\mathrm{CO}_{2}$ laser pulse energy.

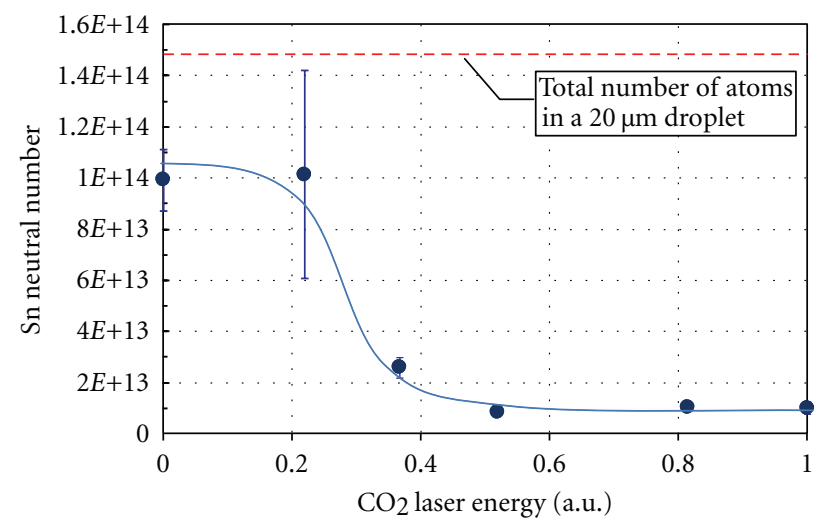

Figure 8: Sn neutral atoms versus $\mathrm{CO}_{2}$ laser pulse energy.

experimental setup [16]. We conducted two experiments using the LIF metrology setup, with and without $\mathrm{CO}_{2}$ laser irradiation, and then by comparing the two resultant signals, we are able to conclude $93 \%$ of the Sn atoms are ionized and $7 \%$ of the $\mathrm{Sn}$ atoms remain as neutral atoms. This ratio changes with $\mathrm{CO}_{2}$ laser pulse energy, as shown in Figure 8 [7]. The experimental results indicate when above a certain threshold of $\mathrm{CO}_{2}$ laser energy, almost all $\mathrm{Sn}$ atoms in the droplet are ionized. This is a very positive result, as it indicates that the Sn ionization rate remains constant when $\mathrm{CO}_{2}$ irradiation energy exceeds a definable minimum energy level.

We measured the ion distribution with the faraday cup measurement [16] with and without a magnetic field. Two faraday cups are set at the position of the collector mirror, where a cup is located in a direction perpendicular to the direction of the magnetic field. The other cup is located where the magnetic flux converges. Based upon the assumption that the average valence of the $\mathrm{Sn}$ ion is two, we calculated the distribution and the collection rate of the ions 
in the magnetic field. We tested with several magnetic field conditions. Figure 9 also indicates that the $\mathrm{Sn}$ ions are collected along the magnetic flux as the magnetic field is enhanced. The collection rate of the ions exceeds $98 \%$ under some magnetic field conditions.

The overall results are summarized; we have observed $30 \%$ fragments, $67 \%$ neutral atoms, and 3\% ions from a $20 \mu \mathrm{m}$ Sn droplet with only prepulse laser irradiation. After irradiate $\mathrm{CO}_{2}$ laser, $0 \%$ of fragments, $7 \%$ of neutral atoms, and $93 \%$ of ions were observed.

3.3. $\mathrm{CO}_{2}$ Laser Energy Consumption Budget. In the previous sections, we discussed Sn behavior during EUV light generation. From the drive laser point of view, we now turn to a discussion of energy transfer from $\mathrm{CO}_{2}$ laser energy into $\mathrm{Sn}$ droplets. In an LPP EUV source, the $\mathrm{CO}_{2}$ laser energy is either absorbed in the plasma, reflected from the plasma, or transmitted through the plasma. The reflected energy of the $\mathrm{CO}_{2}$ laser can further be divided into three subcomponents: (a) reflection back into the $\mathrm{CO}_{2}$ laser, (b) reflection onto the collector mirror, and (c) reflection onto the surrounding vessel wall. Figure 10 graphically shows the defined areas. In order to make an efficient system, it is preferred to maximize the absorbed energy into the $\mathrm{Sn}$ and minimize the reflected and (d) transmitted energy. Reducing the reflected energy back into the $\mathrm{CO}_{2}$ laser will also reduce self-oscillation of the $\mathrm{CO}_{2}$ laser which could limit the maximum power a drive laser could operate and damage components in the laser system. The energy distribution is measured in a plane parallel to the $\mathrm{CO}_{2}$ laser entrance and for calculation purposes the reflected energy is assumed to scatter rotationally symmetric.

Figure 11 summarizes the results of $\mathrm{CO}_{2}$ laser energy distribution with varying prepulse laser energy (pulse duration 10 nsec.). The $\mathrm{CO}_{2}$ laser absorption ratio and $\mathrm{CE}$ increase with increasing prepulse energy. These results demonstrate that higher prepulse pulse energy is very effective to maximize $\mathrm{CO}_{2}$ laser energy absorption into the Sn plasma and minimize transmission and reflection effects. And as expected, another positive aspect of increased prepulse pulse energy is increased absorption leading to improved CE [17].

$\mathrm{CO}_{2}$ laser energy power distributions, under optimized conditions, are summarized $68 \%$ absorption, $26.6 \%$ reflected, and $5.4 \%$ transmitted $\mathrm{CO}_{2}$ laser energy power. The $26.6 \%$ reflected power is further broken down to $3.9 \%$ back reflection into the $\mathrm{CO}_{2}$ laser, $4.6 \%$ towards the collector mirror, and $18.1 \%$ reflected to the vessel walls. In the case of no prepulse irradiation, the transmission energy is significantly larger as $\mathrm{Sn}$ droplet size $(20 \mu \mathrm{m})$ and $\mathrm{CO}_{2}$ laser spot size $(300 \mu \mathrm{m})$ are not matched. Optimal prepulse conditions therefore better match the physical sizes of the $\mathrm{Sn}$ mist to the $\mathrm{CO}_{2}$ beam waist providing very high EUV transmissions with relatively low prepulse energies.

\section{Optimization of Prepulse Laser Irradiation Conditions}

4.1. Sn Target Formation Difference by Pulse Duration of Prepulse Laser. In the previous sections, we have shown the prepulse is key to improve CE and our previous report has indicated higher prepulse energy supports higher CE [17]. However, the prepulse laser power is limited due to size and cost in the system. To improve the CE, we focus on the pulse duration of prepulse laser. Given that the pulse energy is the same, higher peak intensity is obtained with shorter pulse duration than with longer pulse duration. In this study, we conducted experiments using the two setups of the prepulse laser with different pulse durations and comparable pulse energy output. The one has nanosecond (nsec) pulse duration; the other has picosecond (psec) pulse duration. The maximum output of both laser setups is around $2.5 \mathrm{~mJ}$. Table 2 shows the major experimental conditions on the small experimental light source tool that we have reported in the previous sections.

We have conducted tests with the two setups of prepulse laser energy pulse durations. We have compared the following phenomena:

(i) transient phenomena of Sn target shape formations (Table 3);

(ii) CE study by delay time dependency between prepulse laser and $\mathrm{CO}_{2}$ laser with deferent prepulse laser energy (Figure 12 and Figure 13);

(iii) target size expansion speed by prepulse laser energy at different laser pulse duration (Figure 15).

Table 3 shows the comparison of target shape formation in psec and nsec prepulse lasers. The pictures of two different delay time are shown to observe how target shape changes as time goes on. The targets were observed at 90 degree from the lasers irradiation angle. The target will be irradiated with $\mathrm{CO}_{2}$ laser beam when it is expanding around $300 \mu \mathrm{m}$. However, it should be noted that this experiment was conducted without the $\mathrm{CO}_{2}$ laser irradiation because we wanted to see the behavior of target shape change. The delay time between the prepulse laser irradiation and the $\mathrm{CO}_{2}$ laser irradiation is indicated in the same scale in this paper.

Table 4 is summarized major difference of shape formation between the two pulse durations from the pictures of Table 3. Generally, on psec condition, the Sn target expansion speed is fast and fine while the expansion is slow and coarse on nsec condition.

4.2. CE versus Pulse Duration of Prepulse Laser. Figures 12 and 13 show CE difference by delay time dependency between the prepulse laser and the $\mathrm{CO}_{2}$ laser with different prepulse laser energies. When the $\mathrm{Sn}$ target is expanding by prepulse laser irradiation, the shape and fragment size are also changing. These phenomena should affect CE.

Figure 12 shows the case of nsec prepulse laser. When we use nsec prepulse laser, we have obtained maximum 3.4\% $\mathrm{CE}$ at $2.7 \mathrm{~mJ}$ pulse energy. The higher $\mathrm{CE}$ was obtained with higher laser pulse energy. The change in $\mathrm{CE}$ trend is not very significant with delay time change.

Figure 13 shows the case of the psec prepulse laser, we have obtained $4.7 \% \mathrm{CE}$ at $2 \mathrm{~mJ}$ pulse energy. The higher $\mathrm{CE}$ was obtained with higher laser pulse energy. The delay time at highest CE is at 2.5 times faster than nsec prepulse duration. 


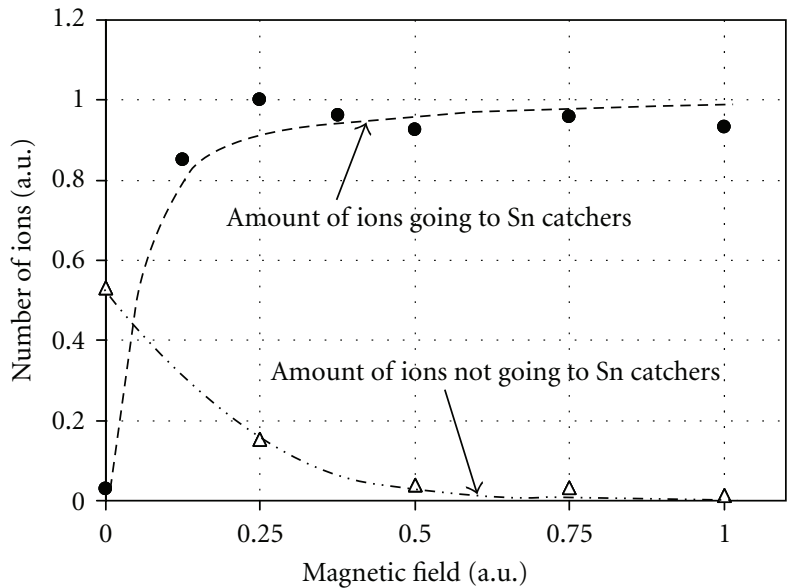

(a)

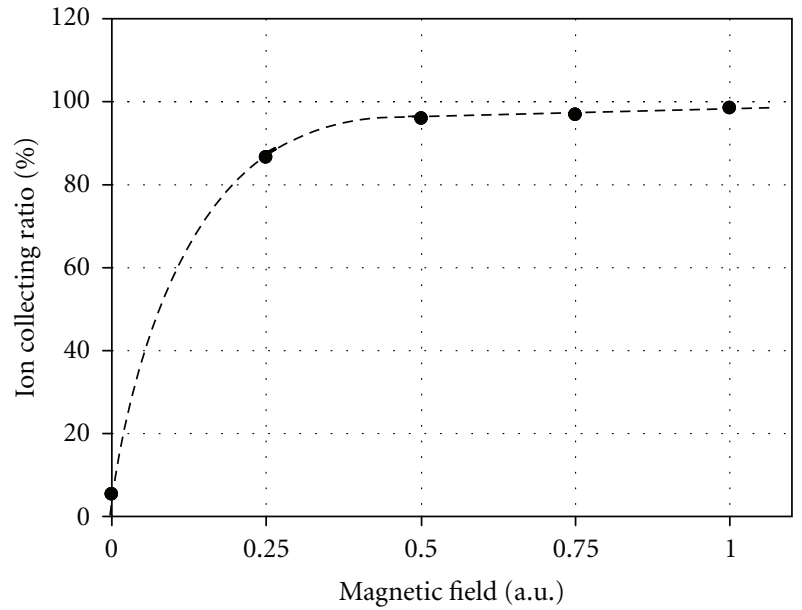

(b)

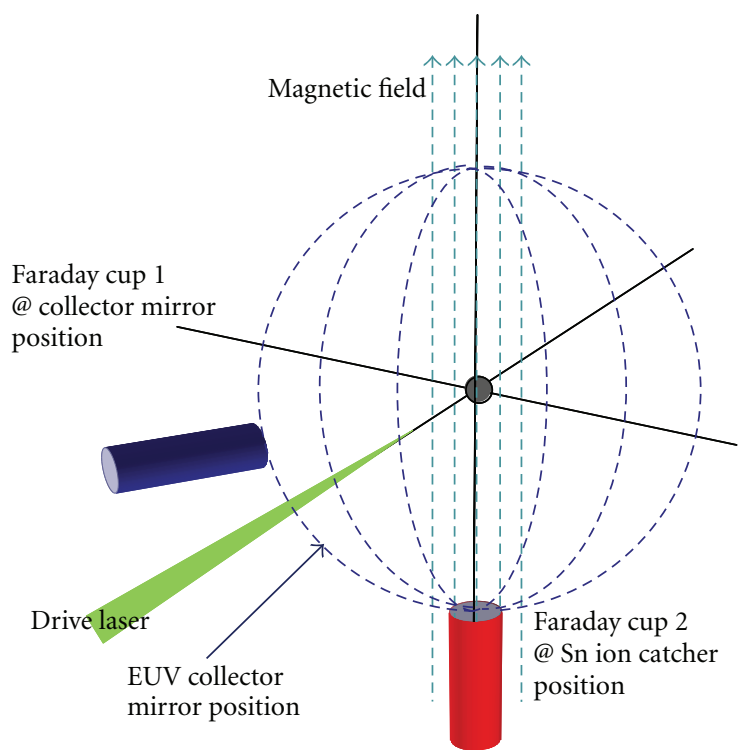

(c)

FIGURE 9: Sn ions collection rate versus magnetic field strength.

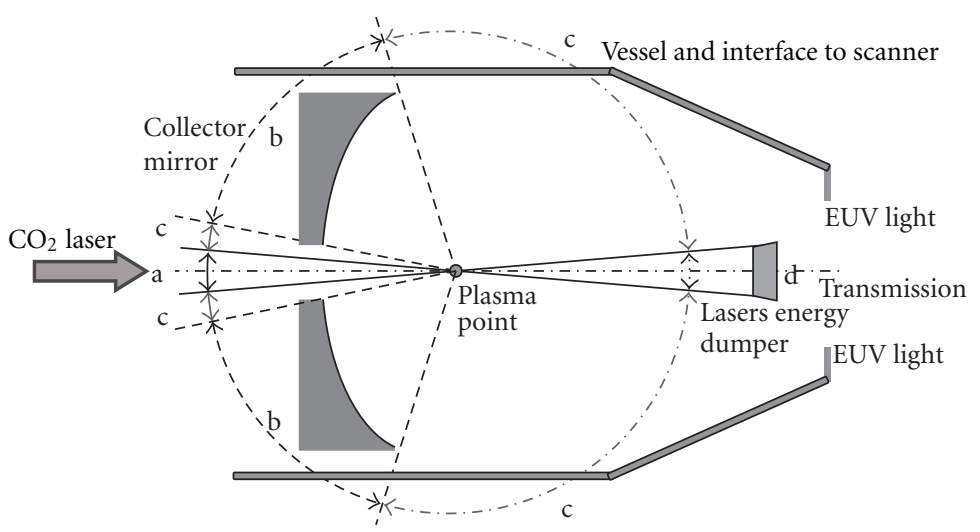

FIGURE 10: Category of reflected $\mathrm{CO}_{2}$ laser energy; (a) reflection back into the $\mathrm{CO}_{2}$ laser, (b) reflection onto the collector mirror, (c) reflection onto the surrounding vessel wall, and (d) transmitted energy. 


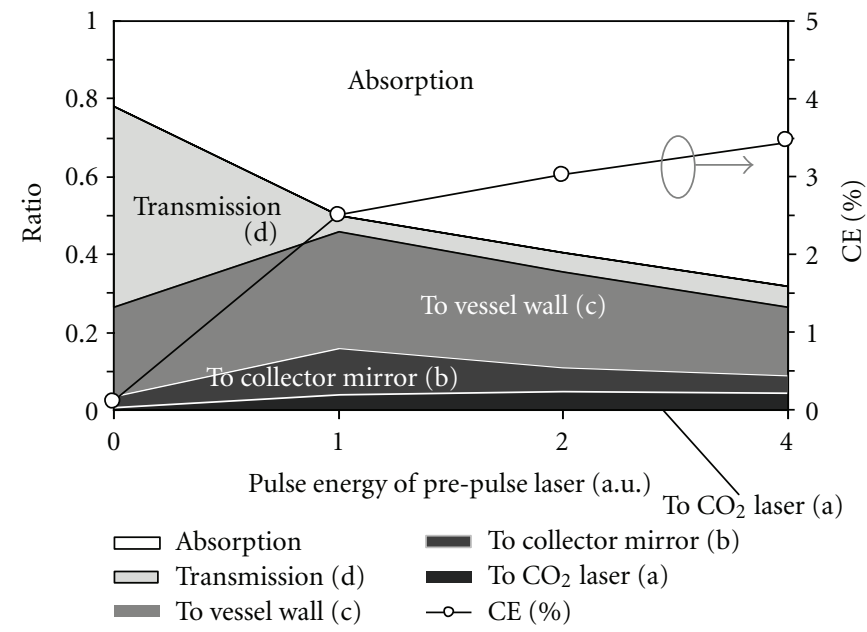

FIGURE 11: $\mathrm{CO}_{2}$ laser energy distribution results versus prepulse condition laser energy.

TABLE 2: Major condition of small experimental light source.

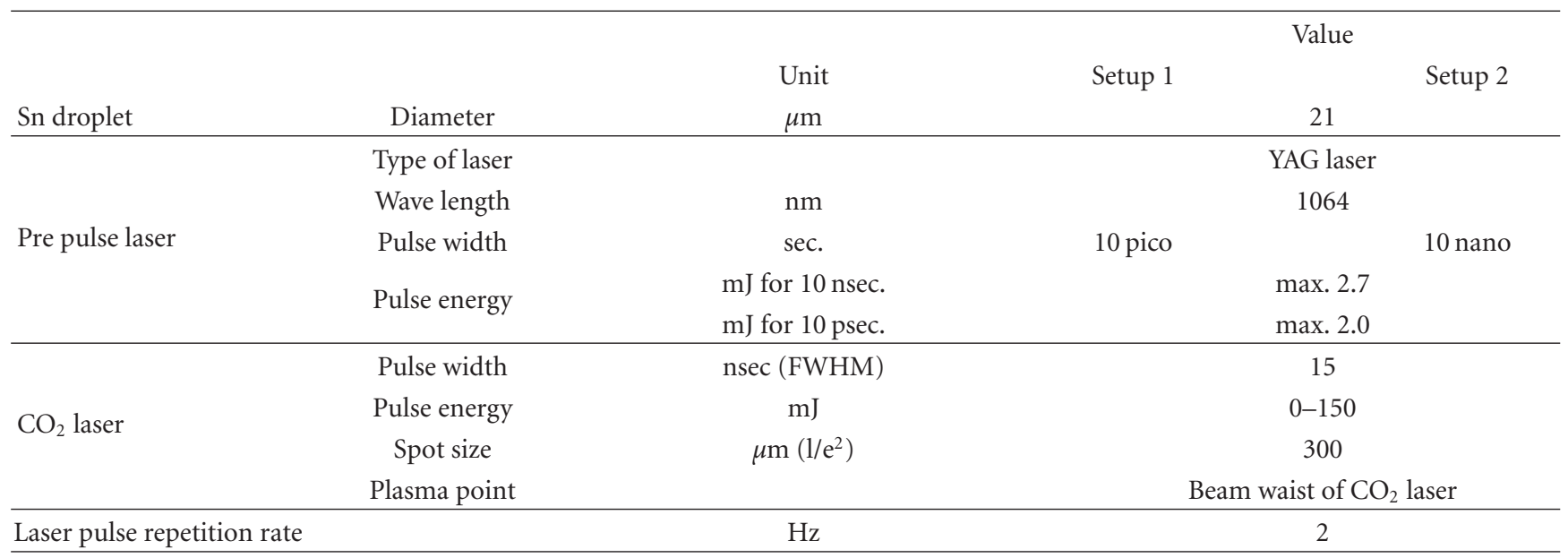

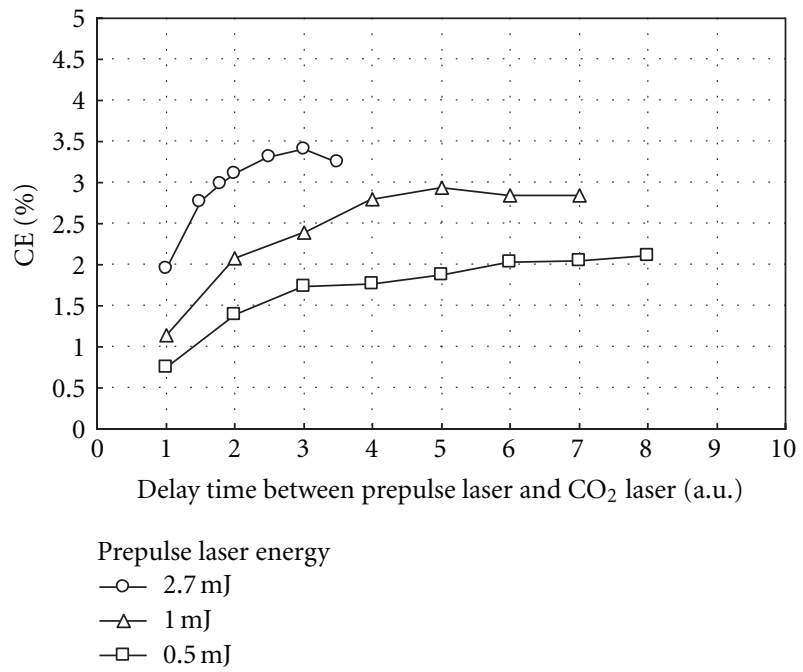

FIGURE 12: CE comparison with laser irradiation delay time between nsec prepulse \& $\mathrm{CO}_{2}$ laser.
The change in CE trend is precipitous with the delay time when the prepulse energy is not less than $0.5 \mathrm{~mJ}$. These results suggest that target expansion speed is faster than psec, but size of Sn fragments are finer than nsec.

Figure 14 shows the relation between the $\mathrm{CE}$ and the prepulse energy on each pulse duration of prepulse laser.

The CE on 10 psec prepulse laser improves around 30 to $50 \%$ from the case of $10 \mathrm{nsec}$ prepulse even though the prepulse laser energy is lower than nsec prepulse. The delay time of each point are optimized.

The speed of target expansion can be measured from the shadow graph pictures of the target as we have showed in the previous section. Figure 15 shows the comparison of the typical target expansion speed at nsec and psec pulse duration of prepulse laser. The speed of target expansion is increased with prepulse laser energy. The speed of psec pulse is about 4 to 5 times faster than that of nsec pulse. The almost maximum CEs on psec prepulse are obtained at $0.5 \mathrm{~mJ}$ or more of prepulse energy as shown in Figure 13. 


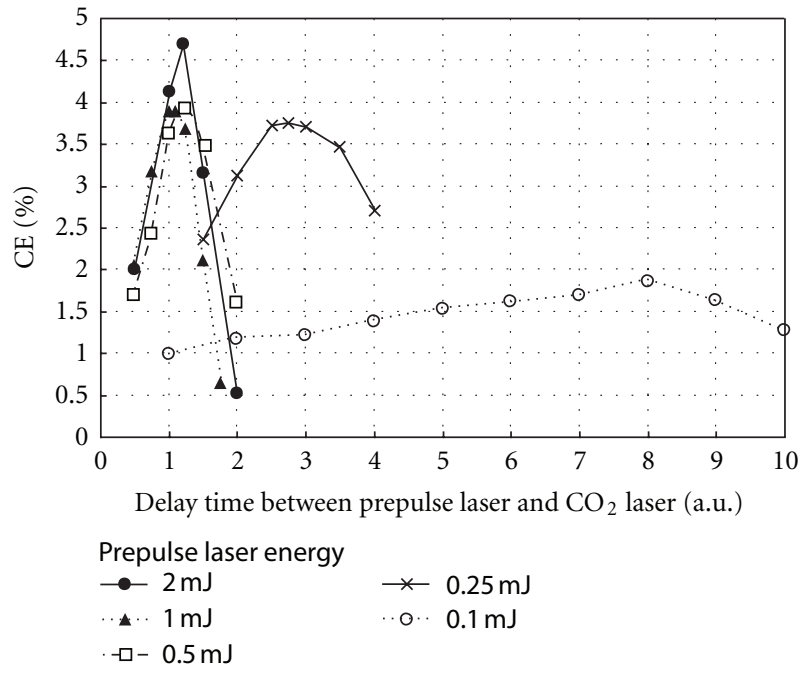

FIGURE 13: CE comparison with laser irradiation delay time between psec prepulse and $\mathrm{CO}_{2}$ laser.

TABle 3: Transient phenomena of Sn target shape with different prepulse laser pulse durations.

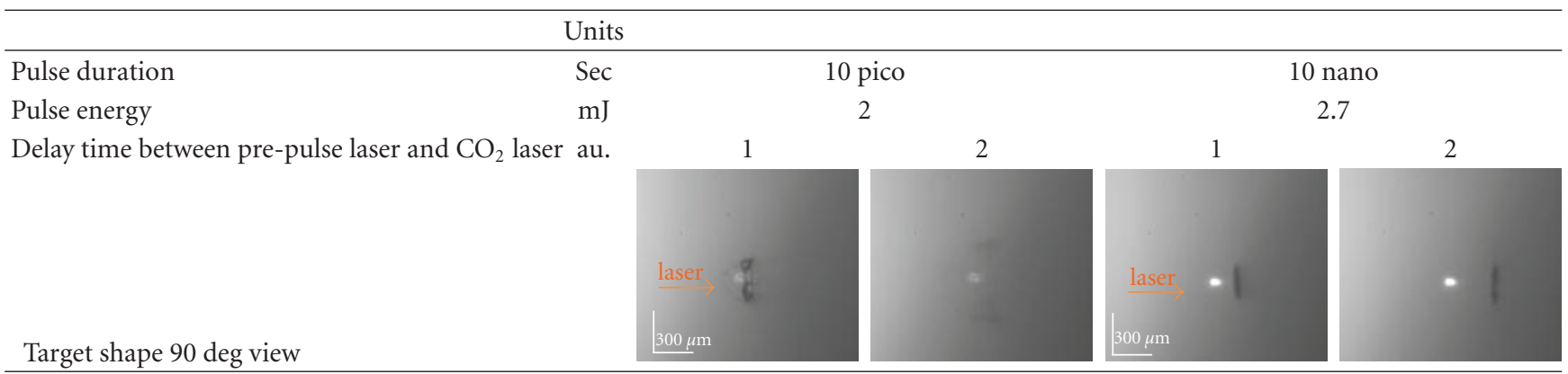

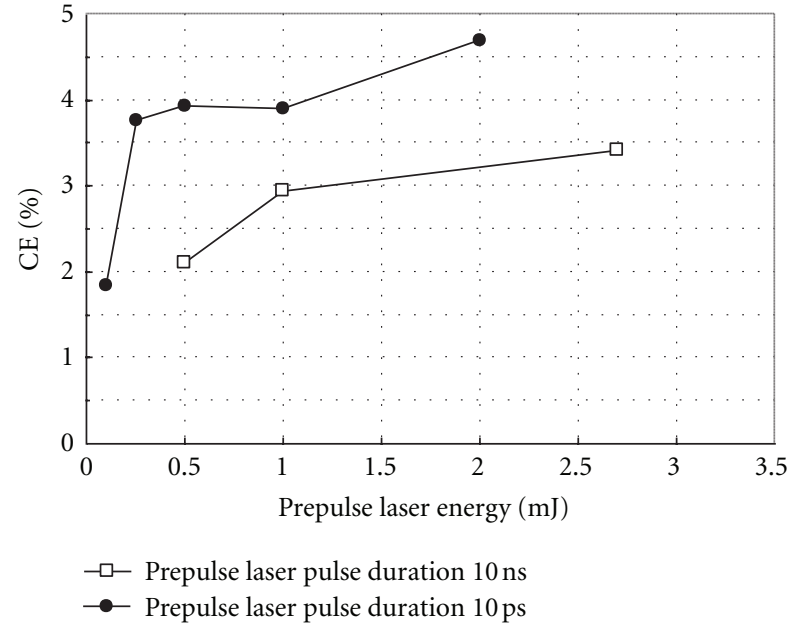

FIgURE 14: CE comparison between nsec and psec prepulse lasers.

When we look the target expansion speed, the change rates of speed are also saturated at $0.5 \mathrm{~mJ}$ or more of prepulse energy. The target size of these conditions is around $300-450 \mu \mathrm{m}$ in diameter, which almost matches or a little bit larger them the $\mathrm{CO}_{2}$ laser beam spot size (around $300-400 \mu \mathrm{m}$ in diameter).

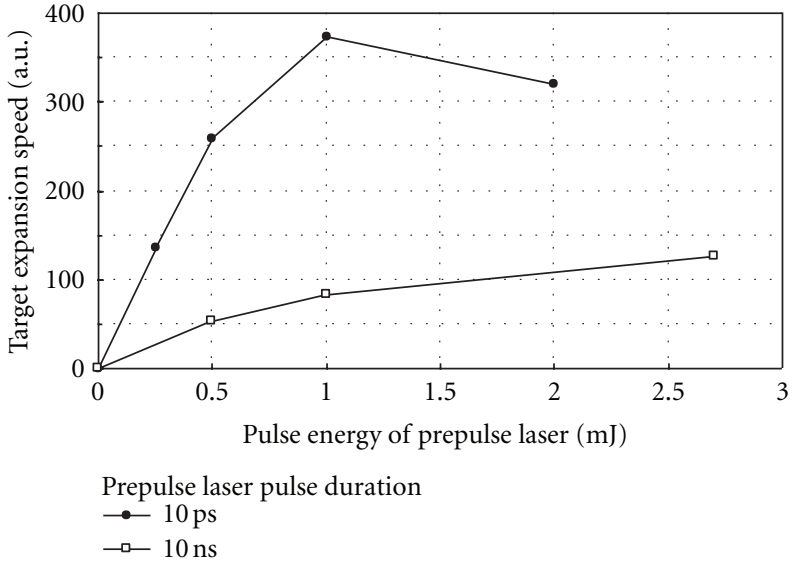

FIGURE 15: target expansion speed comparison between psec and nsec prepulse lasers.

\section{Summary}

We have investigated the EUV plasma generation scheme by use of a small experimental light source tool which operates at less than $10 \mathrm{~Hz}$. We have proposed a double-laser pulse irradiation method to generate Sn plasma efficiently. We 
TABLE 4: Characteristics of target formation between psec and nsec.

\begin{tabular}{|c|c|c|c|}
\hline & Units & & \\
\hline Pulse duration & Sec. & 10 pico & 10 nano \\
\hline Pulse energy & $\mathrm{mJ}$ & 2.0 & 2.7 \\
\hline $\begin{array}{l}\text { Delay time between pre pulse } \\
\text { laser and } \\
\mathrm{CO}_{2} \text { laser }\end{array}$ & au. & 1 and 2 & 1 and 2 \\
\hline \multirow{3}{*}{ Characteristic of target formation } & & $\begin{array}{l}\sqrt{ } \text { Shape of laser side: dome } \\
\text { shape of opposite side: dish }\end{array}$ & $\begin{array}{l}\sqrt{ } \text { Shape of laser side: dish } \\
\text { Shape of opposite side: dish }\end{array}$ \\
\hline & & $\begin{array}{l}\sqrt{ } \text { Target formation scheme; shift to } \\
\text { opposite side of lasers incident } \\
\text { translation speed: slow }\end{array}$ & $\begin{array}{l}\sqrt{ } \text { Target formation scheme: shift to } \\
\text { opposite side of lasers incident } \\
\text { translation speed: fast }\end{array}$ \\
\hline & & $\begin{array}{l}\text { Target expansion speed in diameter: fast } \\
\text { Dispersion of target: fine }\end{array}$ & $\begin{array}{l}\text { Target expansion speed in diameter: slow } \\
\text { Dispersion of target: coarse }\end{array}$ \\
\hline
\end{tabular}
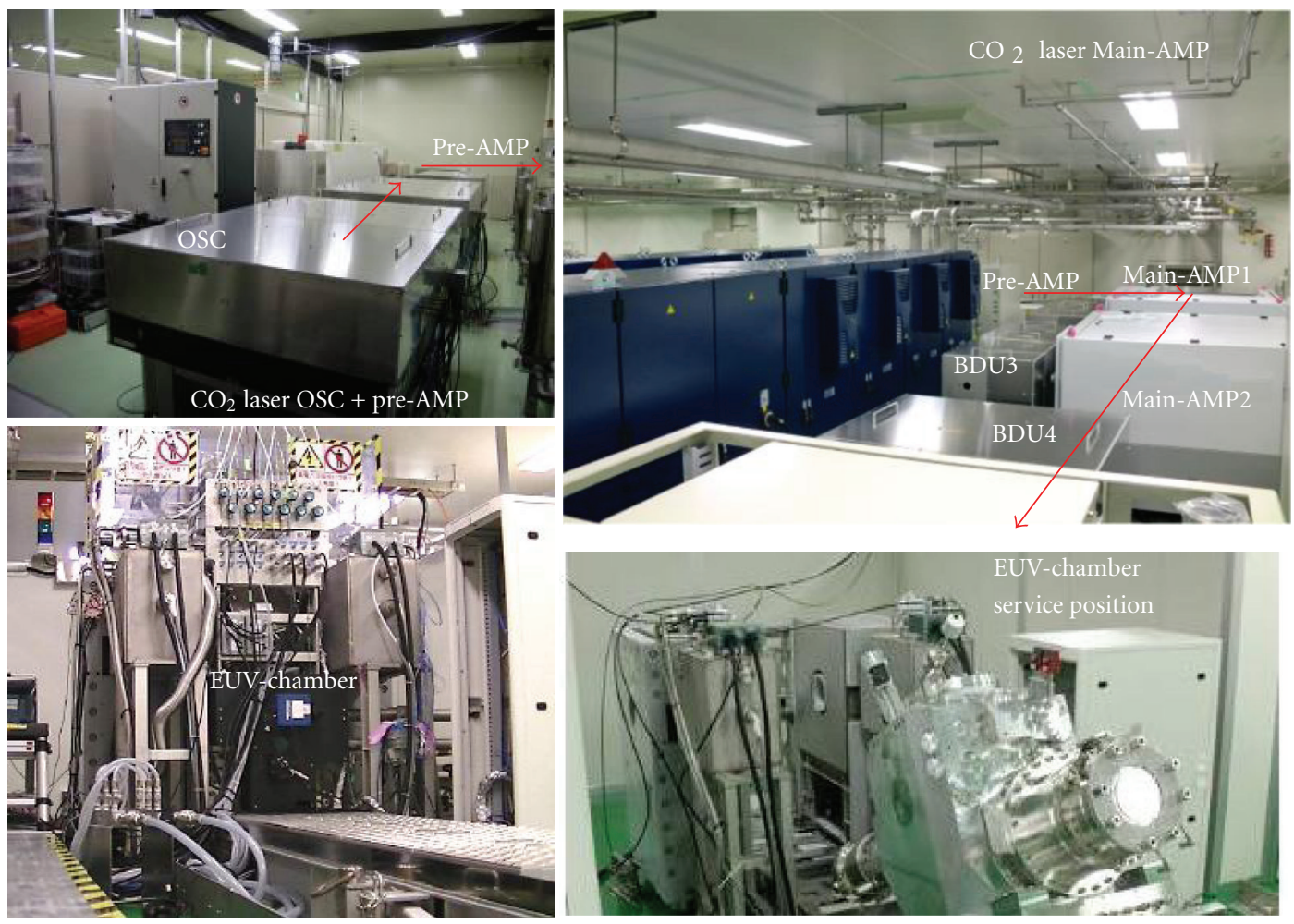

FIGURE 16: Picture of LPP-EUV light source system; Gigaphoton GL200E.

have obtained 93\% Sn ionization rate when the droplets are irradiated with double-laser pulses under proper $\mathrm{CO}_{2}$ laser pulse conditions. Also the $\mathrm{CO}_{2}$ laser absorption ratio is up to $68 \%$, reflected $\mathrm{CO}_{2}$ laser energy back into the $\mathrm{CO}_{2}$ laser is $3.9 \%$.

When we have optimized the prepulse laser pulse duration, we obtained maximum $4.7 \% \mathrm{CE}$ at $2 \mathrm{~mJ}$ prepulse laser energy and with 10 psec pulse duration. The pulse duration of prepulse laser was $10 \mathrm{nsec}$ previously; CE was $3.8 \%$ at a maximum. These results indicate, there is plenty room for improvement on $\mathrm{CE}$ and the prepulse laser output condition to design HVM LPP-EUV source. The efficiency improvement is very important, because it impacts power consumptions, heat load management, system size, and the cost of the whole system.

Based on these engineering results from the small experimental light source tool, we are continuing our development of our first generation EUV light source for HVM: "Gigaphoton GL200E." This system implements the following original concepts:

(1) highly efficient Sn plasma generation driven by pulsed $\mathrm{CO}_{2}$ laser;

(2) double-pulse irradiation scheme for Sn plasma generation; 
(3) Sn debris mitigation by a magnetic field and small $\mathrm{Sn}$ droplet size $(20 \mu \mathrm{m})$;

(4) hybrid $\mathrm{CO}_{2}$ laser system using a combination of a short pulse oscillator and commercial $\mathrm{cw}-\mathrm{CO}_{2}$ amplifiers $[18,19]$.

The design concepts are also reported. These data indicate that our LPP-EUV light source with the magnetic field debris mitigation system will be integrated to the HVM EUVL source system in the near future (Figure 16).

\section{Acknowledgment}

This work was partly supported by the New Energy and Industrial Technology Development Organization (NEDO), Japan.

\section{References}

[1] H. Mizoguchi, T. Abe, Y. Watanabe et al., "1st generation laserproduced plasma source system for HVM EUV lithography," in Proceedings of the SEMATECH Extreme Ultraviolet (EUV) Lithography Symposium, Kobe, japan, 2010.

[2] H. Mizoguchi, T. Abe, Y. Watanabe et al., "1st generation laserproduced plasma source system for HVM EUV lithography," in Extreme Ultraviolet (EUV) Lithography, vol. 7636 of Proceedings of SPIE, 2010.

[3] H. Mizoguchi, T. Abe, Y. Watanabe et al., "100W 1st generation laser-produced plasma light source system for HVM EUV lithography," in Extreme Ultraviolet (EUV) Lithography II, vol. 7969 of Proceedings of SPIE, 2011.

[4] J. Fujimoto, T. Suzuki, H. Nakarai et al., "Development of LPP-EUV Source for HVM EUVL," in Proceedings of the International Symposium on Extreme Ultraviolet (EUV) Lithography, 2011.

[5] T. Hori, T. Yanagida, T. Yabu et al., "Investigation on high conversion efficiency and Tin debris mitigation for laser produced plasma EUV light source," in Proceedings of the SEMATECH Extreme Ultraviolet (EUV) Lithography Symposium, Kobe, JAPAN, 2010.

[6] T. Yanagida, H. Nagano, Y. Wada et al., "Characterization and optimization of tin particle mitigation and EUV conversion efficiency in a laser produced plasma EUV light source," in Extreme Ultraviolet (EUV) Lithography II, vol. 7969 of Proceedings of SPIE, 2011.

[7] J. Fujimoto, T. Abe, S. Tanaka et al., "Laser-Produced Plasma based EUV light source technology for HVM EUV lithography," Journal of Micro/Nanolithography MEMS, and MOEMS, vol. 11, no. 2, 2012.

[8] P. Dunne, G. O'Sullivan, and D. O’Reilly, "Prepulse-enhanced narrow bandwidth soft $\mathrm{x}$-ray emission from a low debris, subnanosecond, laser plasma source," Applied Physics Letters, vol. 76, no. 1, pp. 34-36, 2000.

[9] S. Fujioka, H. Nishimura, K. Nishihara et al., "Opacity effect on extreme ultraviolet radiation from laser-produced tin plasmas," Physical Review Letters, vol. 95, no. 23, Article ID 235004, 4 pages, 2005.

[10] T. Higashiguchi, K. Kawasaki, W. Sasaki, and S. Kubodera, "Enhancement of extreme ultraviolet emission from a lithium plasma by use of dual laser pulses," Applied Physics Letters, vol. 88, no. 16, Article ID 161502, 2006.

[11] T. Higashiguchi, M. Kaku, M. Katto, and S. Kubodera, "Suppression of suprathermal ions from a colloidal microjet target containing Sn O2 nanoparticles by using double laser pulses," Applied Physics Letters, vol. 91, no. 15, Article ID 151503, 2007.

[12] K. Nishihara, A. Sunahara, A. Sasaki et al., "Plasma physics and radiation hydrodynamics in developing," Physics of Plasmas, vol. 15, no. 5, Article ID 056708, 2008.

[13] K. Nishihara, A. Sasaki, A. Sunahara, and T. Nishikawa, EUV Sources for Lithography, Edited by V. Bakshi, chapter 11, SPIE, Bellingham, Wash, USA, 2005.

[14] H. Tanaka, A. Matsumoto, K. Akinaga, A. Takahashi, and T. Okada, "Comparative study on emission characteristics of extreme ultraviolet radiation from $\mathrm{CO}_{2}$ and Nd:YAG laserproduced tin plasmas," Applied Physics Letters, vol. 87, no. 4, Article ID 041503, 3 pages, 2005.

[15] H. Hoshino, T. Suganuma, T. Asayama et al., "LPP EUV light source employing high power $\mathrm{CO}_{2}$ laser," in Emerging Lithographic Technologies XII, vol. 6921 of Proceedings of SPIE, 2008.

[16] Y. Ueno, H. Hoshino, T. Ariga et al., "Characterization of various $\mathrm{Sn}$ targets with respect to debris and fast ion generation," in Emerging Lithographic Technologies XI, vol. 6517 of Proceedings of SPIE, 2007.

[17] J. Fujimoto, T. Hori, T. Yanagida et al., "Development of laserproduced plasma based EUV light source technology for HVM EUV lithography," in Extreme Ultraviolet (EUV) Lithography III, vol. 8322 of Proceedings of SPIE, 2012.

[18] J. Fujimoto, T. Ohta, K. M. Nowak et al., "Development of the reliable $20 \mathrm{~kW}$ class pulsed carbon dioxide laser system for LPP EUV light source," in Extreme Ultraviolet (EUV) Lithography II, vol. 7969 of Proceedings of SPIE, 2011.

[19] T. Ohta, K. M. Nowak, T. Suganuma et al., "Development of the reliable $20 \mathrm{~kW}$ class pulsed carbon dioxide laser system for LPP EUV light source," in Extreme Ultraviolet (EUV) Lithography II, vol. 8322 of Proceedings of SPIE, 2012. 

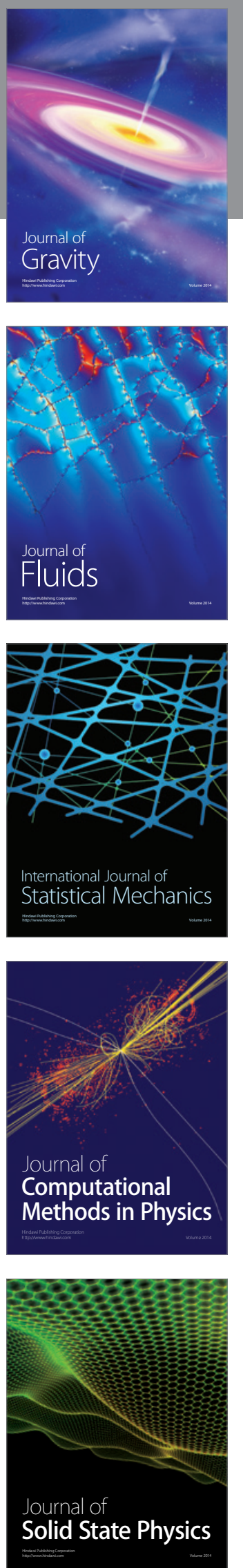

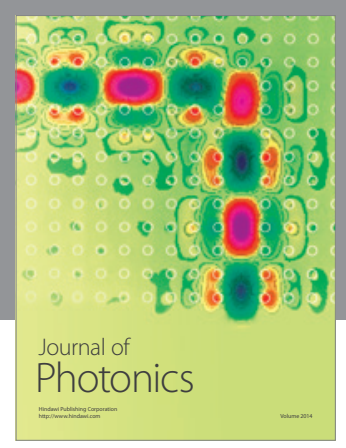

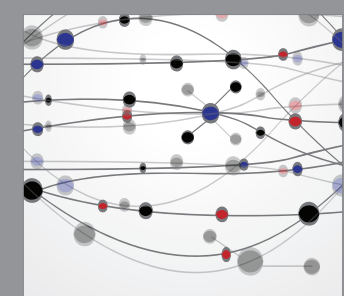

The Scientific World Journal
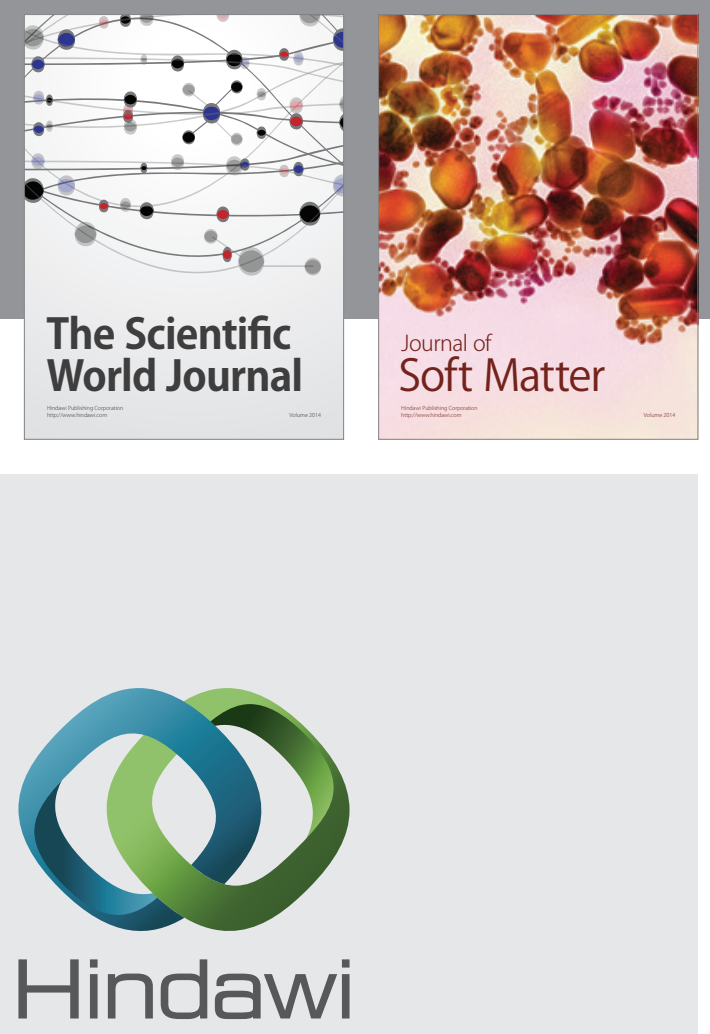

Submit your manuscripts at

http://www.hindawi.com
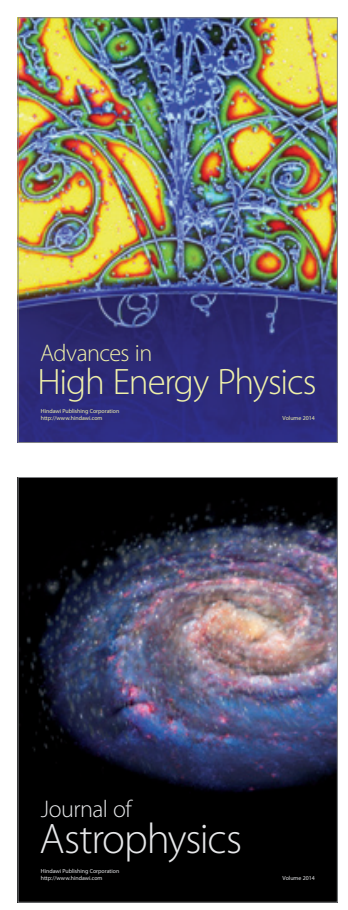
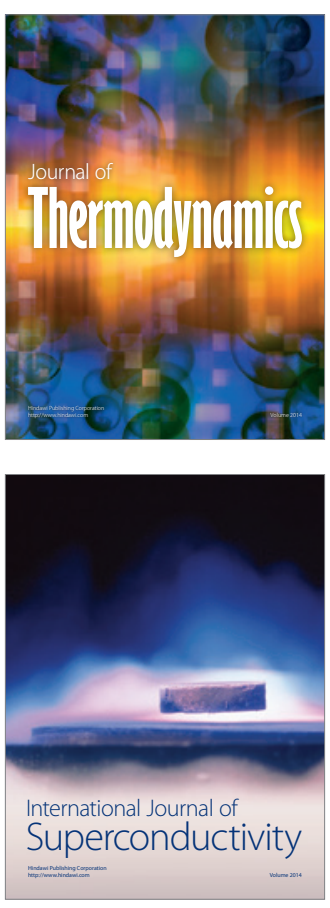
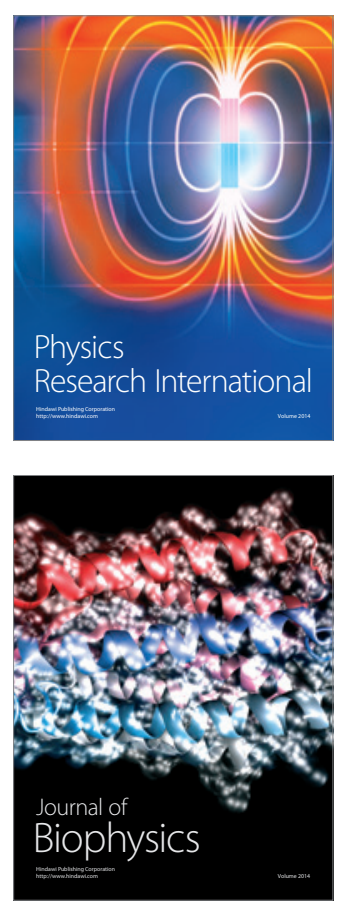
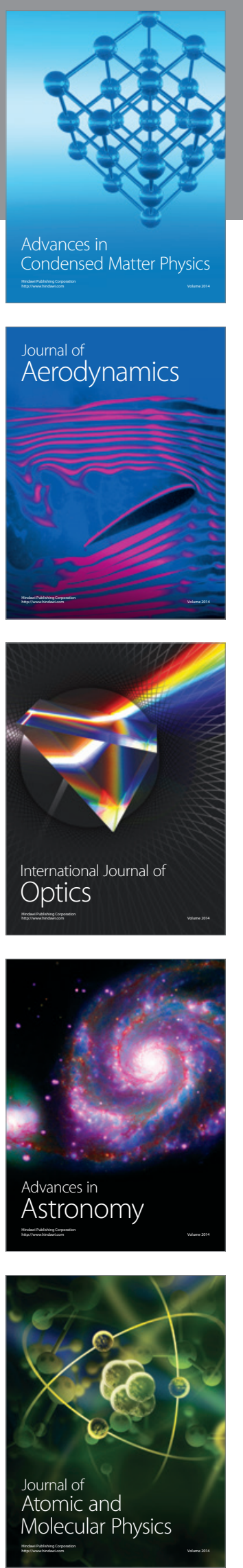